\title{
Eksistensi Perkampungan Setu Babakan Sebagai Daya tarik Wisata Budaya Betawi, Jakarta Selatan
}

Ricky Leonardo Pehulisyaa, 1 , Saptono Nugroho, 2

1rickyleonardopg@yahoo.co.id,2saptono_nugroho@unud.ac.id

a Program Studi Sarjana Destinasi Pariwisata, Fakultas Pariwisata,Universitas Udayana, Jl. Dr. R. Goris, Denpasar, Bali 80232 Indonesia

\begin{abstract}
Babakan Lake is an icon of the Betawi village which was inaugurated by the DKI Jakarta government as a cultural tourist attraction in Jakarta. Betawi arts and culture are increasingly lost by the progress of time. Therefore, the importance of this research is to look at how community participation around villages in promoting Betawi culture in the context of 4A (amenities, accessibility, attractions, institutions). Data collection techniques used in this study were unstructured interviews, observation and documentation. Determination of informants using purposive sampling, data analysis using qualitative. The implementation of tourism activities in Betawi village in the form of facilities, accessibility and institution has fulfilled the criteria as a tourist attraction. Like the Lake Babakan attraction as an icon of the Betawi village. Then also the facilities provided by the government to preserve and advance Betawi villages such as zones that are divided into areas and are motivated by different concepts of each zone. Furthermore, access to the tourist attraction of Lake Babakan has fulfilled the assessment and determination as a tourist area both from the road and the direction of the guide to the location of government and citizens institutions formed by local customary stakeholders. The result of the participation of citizens in tourism activities towards the existence of the Betawi village is that citizens have a role in advancing Betawi art. Suggestions for tourism stakeholders such as government, private sector and citizens in advancing, developing and also preserving the Betawi village is to maintain the existence of the village in the midst of the current development. Such as promoting the existence of a Betawi village to Jakarta residents (millennial, companies, foreign representatives in Jakarta).
\end{abstract}

Keywords: Betawi Cultural Village, Tourism Practices, Existence

\section{PENDAHULUAN}

Penduduk asli Jakarta adalah suku Betawi yang berasal dari percampuran antara berbagai etnis yang dahulunya sudah tinggal atau menetap lama di Jakarta antara lain Jawa, Sunda, Melayu, Bugis dan pendatang lainnya seperti Eropa, China dan Arab. Penduduk asli Jakarta yang disebut sebagai suku Betawi memiliki kampung yang berlokasi di Srengseng Sawah, Jakarta Selatan.

Salah satu Kampung Betawi tersebut digunakan sebagai warisan yang ditetapkan pada 18 agustus tahun 2000. Kampung Betawi terdapat tempat wisata bertema budaya pertama adalah rumah joglo, kedua rumah bapang sebutannya atau dengan kata lain rumah kebaya dan rumah gendang. Selain memiliki rumah adat Betawi, pada saat hari ulang tahun kota Jakrta atau akhir pekan juga menampilkan tarian dan kesenian Betawi dan juga disekitar area danau babakan tersedia jajanan masa kini dan dulu Betawi misalnya kerak telor yang selalu diidentikan dengan makanan khas Betawi, bir pletok yang terdiri dari rempah-rempah, soto Betawi yang tidak kalah enaknya, nasi uduk yang identik dengan sarapan pagi warga Jakarta, es potong, es durian dan masih banyak lagi. Seiring perkembangan jaman dan waktu, perkembangan tersebut selalu menuntut setiap individu untuk berprogres dan Jakarta menjadi pusat bagi setiap orang untuk mencari peruntungan. Kemudian suku Betawi semakin terdesak dengan perkembangan jaman tersebut karena urbanisasi dari kota sekitar Jakarta. Dari kasus diatas perlu melindungi keberadaan kampung Betawi dengan cara menganalisis keberadaan kampung dan keterlibatan warga dalam melestarikan budaya tersebut.

Landasan konsep penelitian ini adalah Konsep 4A fasilitas (amenity), aksesibilitas (Accessibility), atraksi (Attraction), kelembagaan (Ancillary) Cooper dkk (1995: 81). Konsep Daya Tarik Wisata Yoeti (2002: 5). Konsep Kampung Wisata Page \& Connell $(2006,428)$. Konsep Desa Wisata (Nuryanti, 1993) dan terakhir Konsep Eksistensi Masyarakat Lokal dalam pariwisata (Graburn, 1983; Nuruddin, dkk., 2020).

Telaah penelitian pertama yang diteliti oleh Itok Dwi Kurniawan (2018) berjudul "Peran Pendidikan Terhadap Eksistensi Kehidupan Masyarakat Adat Kampung Naga, Tasikmalaya, Jawa Barat" memuat bagaimana pendidikan sangat penting bagi keberadaan kampung naga saat ini. Selanjutnya penelitian kedua yang dilakukan oleh Nurman Yanti (2013) berjudul "Eksistensi Tradisi Juadah Dalam Melestarikan Solidaritas Dalam 
Upacara Perkawinan" nilai-nilai kemanusiaan dalam kehidupan keseharian antara lain bahu-membahu, solidaritas, kekeluargaan dan bersama-sama dalam membuat juadah. Kemudian yang terakhir berjudul "Keterlibatan Masyarakat Pendatang Dalam Pelestarian Budaya Betawi di Perkampungan Setu Babakan Kelurahan Srengseng Sawah Kecamatan Jagakarsa Kota Jakarta” oleh Ika Yanuarizki (2013)

\section{METODE PENELITIAN}

Lokasi kegiatan mencari data berada di kampung Betawi kecamatan Jagakarsa. Atau dengan kata lain lokasi ini akrab disebut dengan danau babakan yang menjadi warisan Jakarta. Selain dijadikan warisan Jakarta, danau babakan dapat dijadikan alternatif bagi warga Jakarta untuk tempat rekreasi keluarga di akhir pekan dan menjadikan fungsi utamanya sebagai resapan air. Ruang lingkup penelitian yang pertama di danau babakan mencakup konsep 4A yaitu : fasilitas (amenitas), aksesibilitas menuju kampung Betawi, atraksi wisata, kelembagaan (ancillary). kemudian ruang lingkup kedua adalah kegiatan warga kampung Betawi terhadap fasilitas, aksesibilitas, atraksi, kelembagaan dan jenis-jenis kontribusi warga.

Jenis data penelitian ini adalah kualitatif (Kusmayadi dan Sugiarto, 2000) berupa kegiatan pariwisata di kampung Betawi seperti amenitas, aksesibilitas, atraksi dan kelembagaan kemudian keterlibatan warga akan kegiatan pariwisata terhadap keberadaan kampung Betawi. Kemudian data kuantitatif (Sugiyono, 2010) berupa keadaan fisik di kampung tersebut guna pembangunan kegiatan pariwisata dan fasilitas umum lainnya. Kemudian demografi dan iklim. Penelitian menggunakan data primer (Bungin, 2009) dan data sekunder (Sugiyono, 2005) dengan observasi (Moleong, 2010), wawancara (Suryawan, dkk., 2017) dan teknik dokumentasi (Bungin, 2007).

Penelitian ini menggunakan teknik analisis data kualitatif model interaktif. Analisis data menggunakan tiga cara yaitu reduksi data, display data, kesimpulan dan verifikasi (Miles dan Huberman, 1992).

\section{HASIL DAN PEMBAHASAN}

\section{A. Gambaran Umum Danau Babakan}

Danau babakan yang berdekatan dengan kampung Betawi adalah salah satu ikon yang terletak didaerah Srengseng Sawah tepatnya di kota administrasi Jakarta Selatan. Danau babakan bagi warga merupakan salah satu tempat untuk bereakreasi bagi keluarga diakhir pekan. Selain untuk berekreasi diakhir pekan, danau babakan yang berdekatan dengan kampung Betawi sering mengadakan kegiatan bernuansakan Betawi di akhir pekan atau hari-hari tertentu yang bersangkutan dengan hari raya Betawi. Selain itu warga yang bukan asli Betawi (pendatang) tetapi tinggal disekitar tersebut, ikut ambil bagian dalam mengisi kegiatan yang diselenggarakan baik dari pihak pemerintah maupun warga itu sendiri.

Dalam sejarah penetapannya pada tahun 70 , isu-isu pembangunan kampung Betawi sebagai cagar dan tempat pelestarian pada awalnya di tahun 2000 baik dari para tokoh adat, badan musyawarah hingga warga Betawi sendiri menetapkan condet sebagai kampung Betawi dibatalkan karena evaluasi bahwa condet sudah terlalu banyak pendatang dari berbagai etnis dan suku. Kemudian beranjak ke daerah marunda berlokasi di Jakarta Utara kemudian hasil penetapannya kembali dibatalkan karena daerah geografis tidak cocok untuk membangun kampung Betawi karena disisi lain suhu udara disana panas dan kurangnya penanaman pohon didaerah tersebut. Dari marunda beranjak ke daerah kemayoran, lokasi sama dengan marunda kemudian penetapannya kembali di batalkan karena pembangunan kampung Betawi membutuhkan ruang banyak sedangkan hanya tersedia 1500 hektar are. Dan akhirnya berdiri sampai saat ini ditetapkan didaerah Srengseng Sawah, Jakarta Selatan yaitu danau babakan yang dijadikan kampung Betawi dan cagar budaya ditetapkan surat keputusan gubernur DKI Jakarta pada saat itu no.9 tahun 2000.

\section{B. Praktik Pariwisata di Daya Tarik Wisata Danau Babakan}

Praktik pariwisata dapat dijelaskan sebagai atraksi wisata yang telah ada di danau babakan termasuk kedalam konteks 4A. konteks $4 \mathrm{~A}$ di kampung Betawi danau babakan dapat dijabarkan sebagai berikut : pertama adalah fasilitas (amenity), yang dibagi menjadi zona A, B, C, embrio dan pengembangan fasilitas sarana prasarana. Kedua adalah aksesibilitas, menuju kampung Betawi dan di kampung Betawi itu sendiri. Ketiga adalah atraksi seperti wisata budaya, air, agronomi dan kegiatan kesenian di kampung Betawi, kelembagaan (ancillary).

\section{Fasilitas (amenity)}

Fasilitas yang berada di kampung Betawi, dibagi menjadi zona A, B, C, embrio dan pengembangan fasilitas sarana prasarana dimana setiap zona tersebut memiliki konsep dan tujuan masing-masing. 


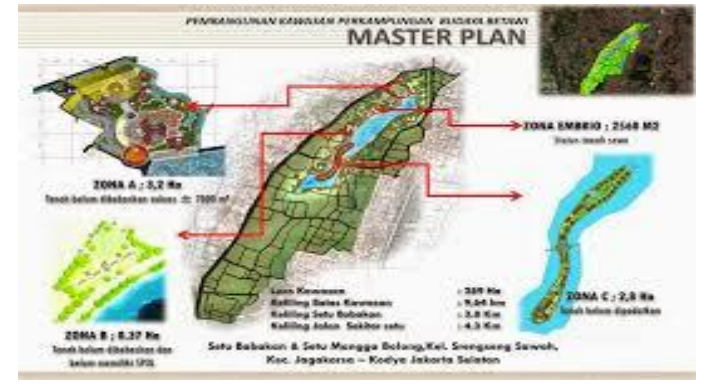

Gambar 3. Peta Master Plan Sumber : Perkampungan Budaya Betawi 2019

Zona A memiliki konsep yang mengusung sebagai tempat pelestarian kesenian Betawi (formal) seperti museum Betawi yang didalamnya terdapat koleksi-koleksi batik Betawi, baju khas abang none, replika mini oplet si doel, sepeda ontel, alat musik tanjidor dan peralatan dapur tempo dulu. Kemudian amphitheater yang digunakan untuk pentas atraksi. Atraksi yang dibawakan biasanya seni tari, seni musik dan drama. Panggung pentas ini juga dilengkapi dengan microphone, tape recorder, speaker, kaca hias, toilet, audio mix dan kursi. Dalam hal kegiatan kesenian, warga yang mendaftarkan dirinya untuk mengikuti kegiatan kesenian Betawi, biasanya melakukan latihan rutin setiap hari Rabu dan Kamis di panggung teater ini. kemudian warga yang bertempat tinggal disekitar kampung Betawi diharuskan oleh pemerintah yang diatur dalam peraturan daerah no 3 pasal 8 tahun 2005 untuk memiliki rumah yang berasitektur Betawi agar memberikan edukasi terhadap pengunjung yang berwisata ke kampung Betawi. Rumah ibadah yang dibangun oleh pemerintah setempat untuk kebutuhan rohani para pengunjung dan warga sekitar seperti masjid At-Taubah dan mushola AlFalaah yang pembangunannya mengusung konsep budaya Betawi . Kawasan wisata kampung Betawi memiliki 1 buah toilet yang terpisah antara pria dan wanita yang terletak di zona wisata seni berdekatan dengan mushola dan dikondisikan dengan baik dan terawat. Kemudian zona A memiliki Gedung serbaguna yang dibangun pada tahun 2015 silam kini pembangunannya hampir selesai. Gedung serbaguna ini berbentuk bulat dengan warna putih dan bertema kayu yang sangat megah. Gedung serbaguna ini rencananya di bangun untuk teater tertutup, perpustakaan dan galeri khas Betawi. kantor pengelola (rumah kebaya) kantor untuk pengurus lembaga kampung Betawi melaksanakan fungsi, tugas dan kegiatan pengelolaan sehari-hari.

Konsep yang digunakan pada zona B diperuntukan sebagai kawasan tempat makan atau jajanan Betawi yang disediakan oleh pemerintah dan pemerintah sama sekali tidak memungut pajak retribusi atas lapak yang telah diberikan. Selain itu terdapat forum para pedagang kaki lima danau babakan yang dikordinir langsung dari unit pengelola kawasan kampung Betawi yang sewaktuwaktu memberikan informasi mengenai festival yang berlangsung kedepannya.

Zona ini brand dari unit pengelola kawasan kampung Betawi yaitu zona $\mathrm{C}$ yang pada saat ini pembangunannya sedang berjalan. Proyek tersebut kedepannya akan membangun replika rumah adat Betawi jaman dulu yang berlokasi ditengah pulau danau babakan. Kemudian yang terakhir adalah zona embrio dan pengembangan fasilitas sarana dan prasarana yang bertujuan untuk melestarikan kampung Betawi, dibangun kantor pengelola untuk zona embrio dan menghasilkan sumber daya manusia yang unggul dengan membangun sekolah kejuruan di zona pengembangan fasilitas sarana dan prasarana.

\section{Aksesibilitas (accessibility)}

Aksesibilitas di bagi menjadi dua yaitu, pertama jalan menuju kampung Betawi dan yang kedua jalan di kampung Betawi. Selama melakukan kegiatan penelitian, peneliti melihat bahwa jalan menuju kampung Betawi dari arah pasar minggu begitu juga sebaliknya sedikit sempit. Tetapi jalan sudah dilengkapi dengan plang-plang penunjuk jalan menuju ke lokasi kampung Betawi dan juga sangat membantu wisatawan dari dalam atau luar negeri yang ingin berkunjung pertama kalinya dengan adanya aplikasi (google maps) yang tersedia di handphone. Kemudian jalan yang berada disekitar kampung Betawi belum diaspal dengan baik dan masih menggunakan conblock dan beberapa jalan masih belum mengunakan apa-apa atau masih dari tanah merah. Wacana kedepannya menuju lokasi kampung Betawi adalah jalanan di perlebar dengan membebaskan lahan warga. Latar belakang wacana pelebaran jalan menuju lokasi adalah pada waktu itu saat Presiden Joko Widodo menghadiri kegiatan lebaran Betawi di danau babakan menyadari bahwa jalan menuju lokasi sempit, maka di wacanakan kedepannya untuk pelebaran jalan menuju kampung Betawi dengan membebaskan lahan warga. Dan wacana kedua akan di bangun kereta gantung mulai dari kebun binatang ragunan sampai ke stasiun kreta api lenteng agung yang sedang dibicarakan dengan DISHUB (Dinas Perhubungan DKI Jakarta).

\section{Atraksi (attraction)}

Terdapat beberapa atraksi wisata di kampung Betawi seperti atraksi wisata budaya, olahraga air, atraksi wisata agronomi, kegiatan kesenian di kampung Betawi. 


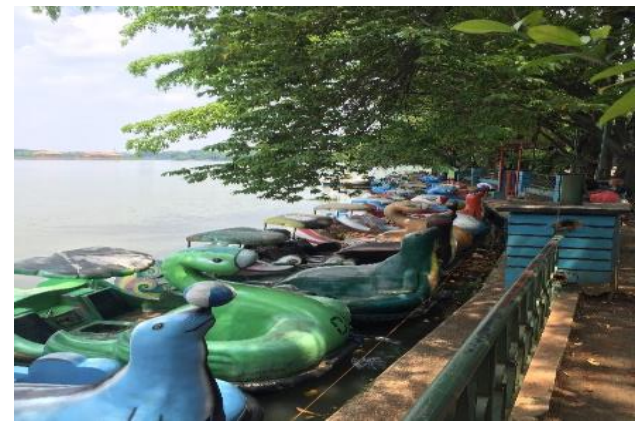

Gambar 1. Sepeda gayung

Sumber : Penelitian Lapangan 2019

Atraksi wisata budaya dibagi menjadi tiga jenis kegiatan : pertama adalah kegiatan pagelaran seni tari, musik dan teater tradisional Betawi. Kedua adalah kegiatan pelatihan seni musik, tari dan teater tradisional Betawi. Kemudian yang terakhir adalah hasil dari indsutri rumahan yang dibuat oleh warga kampung Betawi seperti souvenir (gantungan kunci, boneka ondel-ondel, dan baju khas Betawi), jajanan Betawi (bir pletok, kerak telor, dodol, wajik, kue rangi dan rengginang).

Kegiatan olahraga air seperti memancing, warga setempat maupun pendatang yang berkunjung ke danau babakan, sepeda gayung berbentuk bebek yang berisi dua orang sisi kanan dan kiri dan olahraga cano yang bisa disewakan perjamnya dengan harga yang relatif murah.

Atraksi wisata agronomi yang terdapat di kampung Betawi berbeda dengan wisata agronomi pada umumnya yang memiliki lahan khusus untuk melakukan kegiatan pertanian. Wisata agronomi yang terdapat di kampung Betawi dengan memanfaatkan lahan rumah penduduk yang ditanami berbagai macam tanaman dan buah dengan tujuan untuk pengetahuan, mengasah keterampilan dalam bercocok tanam dan memberikan pemasukan bagi warga dalam bidang pertanian.

Agenda kegiatan kesenian terbagi dalam tiga jenis kegiatan diantaranya tahunan yang dilangsungkan pada hari raya lebaran, festival, kegiatan yang bernuansa islami dan kegiatan akhir tahun dibulan desember. Kegiatan rutin diakhir pekan pada hari sabtu dan minggu yang diprakarsai oleh pengelola kawasan kampung Betawi seperti lenong Betawi kini berubah nama menjadi komedi Betawi yang diperankan oleh artis-artis Betawi senior dan juga masa kini.

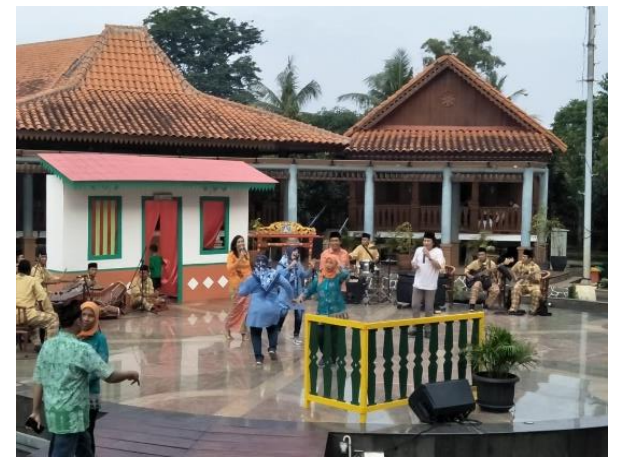

Gambar 2. Komedi Betawi (Lenong) Sumber : Penelitian Lapangan 2019

\section{Kelembagaan (ancillary)}

Kawasan kampung Betawi yang memiliki lahan seluas 289 Ha dengan presentase $100 \%$, lahan yang baru saja dibebaskan oleh pemerintah hingga saat ini $30 \%$ dan sisanya $70 \%$ milik warga. Dari total $30 \%$ lahan yang telah dibebaskan oleh pemerintah, tidak hanya dikelola oleh Dinas Pariwisata saja tetapi terdapat berbagai satuan kerja perangkat daerah (SKPD) dan unit kerja perangkat daerah (UKPD) yang mengelolanya. Hasil dari luas total 289 $\mathrm{Ha}$, lahan yang baru dimiliki oleh pemerintah seluas $7 \mathrm{Ha}$.

Dari total luas lahan yang dibebaskan dan dimiliki pemerintah seluas $7 \mathrm{Ha}$, badan pemerintah yang mengelola kampung Betawi diantaranya adalah dinas pariwisata dan permusiuman, tata kota, pertamanan, pertanian dan kehutanan, kebersihan, perhubungan dan biro administrasi sarana perkotaan DKI Jarkarta yang dimana badan pemerintah tersebut melaksanakan tugas dengan tujuan masing-masing dan saling membutuhkan satu sama lain untuk kemajuan kampung Betawi. Selain dikelola langsung oleh badan pemerintahan, kampung Betawi juga dikelola oleh lembaga warga yang tugasnya juga membantu badan pemerintah demi satu tujuan untuk memajukan kampung Betawi seperti lembaga BAMUS atau disebut badan musyawarah Betawi, LKB lembaga kebudayaan Betawi dan SATGAS PBB gerakan sosial perkampungan budaya Betawi.

\section{Implikasi praktik pariwisata terhadap eksistensi}

Keterlibatan warga dalam kegiatan wisata terhadap keberadaan kampung Betawi diuraikan dalam 4A yang dilakukan secara institusional atau non individual. Keterlibatan masyarakat secara institusional melalui BAMUS atau disebut badan musyawarah Betawi, LKB lembaga kebudayaan Betawi dan SATGAS PBB gerakan sosial perkampungan budaya Betawi dimana lembaga ini bekerjasama dengan lembaga pemerintahan 
perkampungan budaya Betawi dalam aktifitas warga terhadap fasilitas, aksesibilitas, atraksi, kelembagaan dan jenis-jenis kontribusi warga sekitar. Keterlibatan warga dalam melestarikan kampung Betawi bidang fasilitas dengan memanfaatkan beberapa fasilitas yang telah disediakan oleh pemerintah setempat bertujuan untuk melestarikan seperti tempat untuk berjualan makanan dan jajanan Betawi dimana warga memiliki potensi bekerja dan memiliki usaha dibidang makanan dan jajanan Betawi. Pemerintah juga menyediakan tempat di amphitheater bagi sanggar-sanggar yang ingin pentas dan berkarya. Kemudian setiap kali pemerintah melaksanakan kegiatan dalam rangka melestarikan seperti workshop cara pembuatan jajanan, ondel-ondel mini Betawi yang dimana peserta kegiatan workshop tersebut adalah anakanak sekolah yang sedang berkunjung ke kampung Betawi, warga ikut ambil bagian dalam kegiatan tersebut guna mengajarkan dan memperkenalkan kepada wisatawan dan generasi penerus agar tidak dimakan perkembangan jaman. Jadi, hubungan antara pemerintah dengan warga sangat dekat dan tidak ada konflik diantara kedua belah pihak oleh karena itu setiap kali ingin mengadakan acara yang selalu mengikutsertakan warga dan warga juga memasarkan bagaimana kampung Betawi adalah salah satu tujuan wisata.

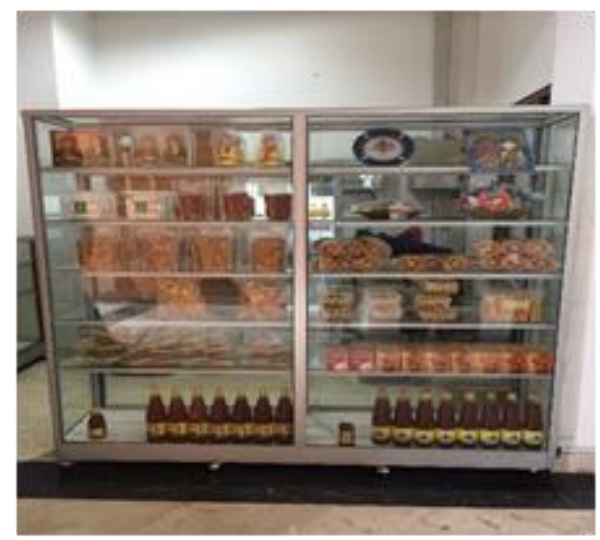

Gambar 4. Etalase di Lobby UPK PBB danau Babakan

Sumber : Penelitian Lapangan 2019

Keterlibatan warga dalam melestarikan kampung Betawi bidang aksesibilitas dengan melakukan pengendalian arus kendaraan keluar masuk dari arah pasar minggu maupun sebaliknya pada saat festival maupun ulang tahun Betawi dari lima wilayah DKI Jakarta seperti Jakarta Pusat, Selatan, Timur, Barat dan Kepulauan Seribu yang berlangung di kampung Betawi agar tidak terjadi penghambatan dan menggangu kenyamanan orang lain dan dikoordinir oleh SATGAS PBB gerakan sosial perkampungan budaya Betawi dan DISHUB (Dinas Perhubungan DKI Jakarta).

Keterlibatan warga dalam melestarikan kampung Betawi bidang atraksi menurut hasil wawancara peneliti kesalah satu pedagang dodol turun temurun dan juga warga yang sudah hidup puluhan tahun bernama angga disekitar danau babakan tersebut menjelaskan bahwa kegiatan para pedagang disekitar bantaran danau babakan yang ikut serta gotong royong dalam menjaga kebersihan lingkungan dan juga danau babakan yang dilakukan setiap 2 minggu sekali di hari jumat pagi mengingat bahwa warga sadar akan kegiatan pariwisata dan kampung Betawi juga danau babakan menjadi salah satu destinasi unggulan di Jakarta Selatan maka dari itu warga yang bertempat tinggal di daerah itu khususnya para pedagang kaki lima sangat menjaga kebersihan danau babakan juga kegiatan gotong royong tersebut dibantu oleh badan pemerintah yang terdapat di kampung Betawi.

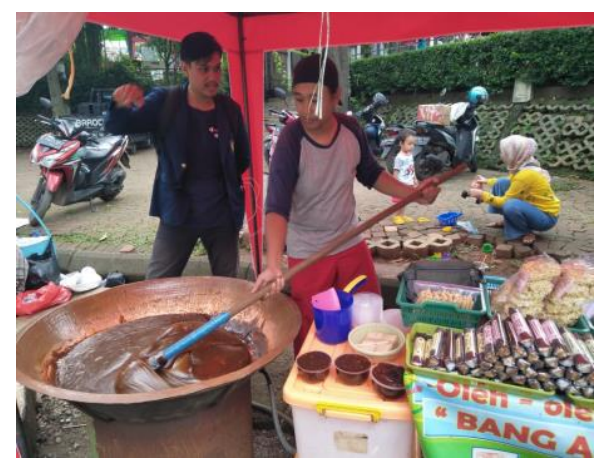

Gambar 5. Pedagang dodol dan juga warga yang bernama angga

Sumber : Penelitian Lapangan 2019

Terakhir dibidang kelembagaan terlibat dalam organisasi yang dibentuk oleh pemuka tokoh adat kampung Betawi yang berada didaerah danau babakan seperti lembaga BAMUS atau disebut badan musyawarah Betawi, LKB lembaga kebudayaan Betawi dan SATGAS PBB gerakan sosial perkampungan budaya Betawi yang dimana organisasi institusional ini membantu pemerintah demi satu tujuan yaitu memajukan kampung Betawi. hasil dari Jenis kontribusi warga dalam penelitian ini adalah kontribusi terdorong, dengan keterlibatan warga dalam atraksi adalah warga maupun pedagang kampung Betawi danau babakan setiap 2 minggu sekali di hari Jumat pagi melakukan gotong royong dalam menjaga kebersihan lingkungan. Fasilitas, warga ambil bagian dalam kegiatan workshop atau acara yang di gelar oleh pemerintah untuk memperkenalkan kepada wisatawan yang berkunjung. aksesibilitas, kontribusi warga salah satunya membantu instansi pemerintah dinas 
perhubungan dalam mengamankan jalur arus kendaraan keluar masuk dari arah pasar minggu maupun sebaliknya pada saat festival maupun ulang tahun Betawi dari lima wilayah DKI Jakarta seperti Jakarta Pusat, Selatan, Timur, Barat dan Kepulauan Seribu yang berlangung di kampung Betawi agar tidak terjadi penghambatan dan menggangu kenyamanan orang lain. Kontribusi warga yang terakhir adalah kelembagaan, warga terlibat dalam organisasi yang dibentuk oleh pemuka tokoh adat warga kampung Betawi yang berada didaerah danau babakan.

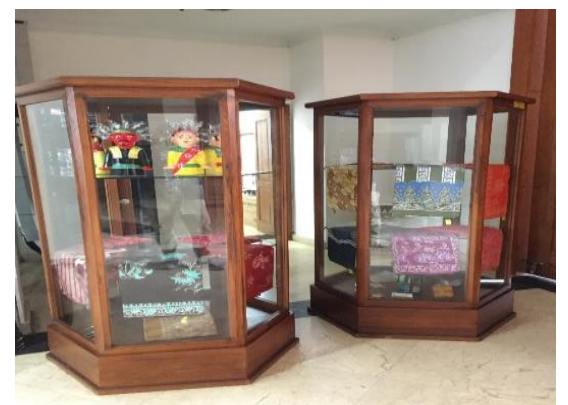

Gambar 6. Hasil kerajinan dari warga Sumber : Penelitian Lapangan 2019

\section{KESIMPULAN}

Praktik pariwisata di perkampungan Setu Babakan dilakukan secara institusional oleh lembaga BAMUS atau disebut badan musyawarah Betawi, LKB lembaga kebudayaan Betawi dan SATGAS PBB gerakan sosial perkampungan budaya Betawi. Lembaga ini bekerjasama dengan lembaga pemerintahan perkampungan budaya Betawi dalam aktifitas warga terhadap fasilitas, aksesibilitas, atraksi, kelembagaan dan jenis-jenis kontribusi warga sekitar kemudian untuk non individual seperti di bidang fasilitas dengan memanfaatkan beberapa fasilitas yang telah disediakan oleh pemerintah setempat untuk masyarakat bebas berekspresi dan berkarya. Bidang aksesibilitas dengan melakukan pengendalian arus kendaraan saat sedang dilakukannya festival kebudayaan di kampung Betawi, bidang atraksi ikut serta gotong royong dalam menjaga kebersihan lingkungan dan juga danau babakan yang dilakukan setiap 2 minggu sekali di hari jumat pagi mengingat bahwa warga sadar akan kegiatan pariwisata dan kampung Betawi juga danau babakan menjadi salah satu destinasi unggulan di Jakarta Selatan dan bidang kelembagaan terlibat dalam organisasi yang dibentuk oleh pemuka tokoh adat kampung Betawi yang berada didaerah danau babakan

\section{DAFTAR PUSTAKA}

Anonim, 2009. Undang-Undang Republik Indonesia Nomor 10.Tahun 2009 Tentang Kepariwisataan.

Bungin, Burhan. 2007. Penelitian Kualitatif: Komunikasi, Ekonomi, Kebijakan Publik dan Ilmu Sosial lainnya.Jakarta:Putra Grafika

Bungin, Burhan. 2009. Analisis Penelitian Data Kualitatif. Jakarta: Raja Grafindo.

Cooper, dkk. 1995. Tourism, Principles and Practice. Prentice Hall, Harlow.

Graburn, N. H. (1983). The anthropology of tourism. Annals of tourism research, 10(1), 9-33.

Itok, Kurniawan Dwi. 2018. "Peran Pendidikan Terhadap Eksistensi Kehidupan Masyarakat Adat Kampung Naga, Tasikmalaya, Jawa Barat", Jurnal Peran Pendidikan Vol. 13 No. 01.

Kusmayadi dan Sugiarto, E., 2000, Metodologi Penelitian dalam Bidang Kepariwisataan, Jakarta: PT. Gramedia Pustaka Utama.

Mahagangga, I. G. A. O., Sos, S., Anom, I. P., Par, M., \& Suryasih, I. A. KAJIAN PENGEMBANGAN DESA WISATA DI KABUPATEN BADUNG.

Miles, M. B., \& Huberman, A. M. (1992). Analisis Data Kualitatif: Buku Sumber Tentang Metode-Metode Baru. Jakarta.

Moleong, Lexy J. 2010. Metodologi Penelitian Kualitatif. Bandung: Remaja Rosdakarya.

Nurman, Yanti Fardayanti. 2013. "Eksistensi Tradisi Juadah Dalam Melestarikan Solidaritas Dalam Upacara Perkawinan (Studi di Korong Kampung Ladang Kabupaten Padang Pariaman", Jurnal Eksistensi Tradisi Juadah Vol. 12 No. 01.

Nuruddin, S. S., Ardika, I. W., Kristianto, Y., Mahagangga, G. A. O., Suryawan, I. B., \& Sendra, I. M. (2020). Portrait of tourism object in Bongan Tabanan Bali village: Cultural studies perspective. Utopía y praxis latinoamericana: revista internacional de filosofía iberoamericana y teoría social, 25(2), 75-85.

Nuryanti, Wiendu. 1993. Concept, Perspective and Challenges. makalah bagian dari Laporan Konferensi Internasional mengenai Pariwisata Budaya. Yogyakarta: Gadjah Mada University Press.

Sugiyono, 2010. Metode Penelitian Pendidikan Pendekatan Kuantitatif, kualitatif, dan R\&D. Bandung: Alfabeta.

Sugiyono, 2005. Memahami Penelitian Kualitatif. Bandung: Alfabeta.

Suryawan, I. B., \& Mahagangga, I. G. A. O. (2017). Penelitian Lapangan 1. Denpasar: Cakra Media dan Fakultas Pariwisata Universitas Udayana.

Yoeti, 2002. Perencanaan Strategis Pemasaran Daerah Tujuan Wisata. Jakarta: PT. Pradnya Paramita. 